EPRA International Journal of Economic and Business Review-Peer Reviewed Journal

Volume - 9, Issue -3, March 2021 | e-ISSN: 2347 - 9671| p- ISSN: 2349 - 0187

\title{
MULTIDIMENSIONAL POVERTY AND INEQUALITY IN ZAWLNUAM BLOCK OF MAMIT DISTRICT, MIZORAM
}

\begin{tabular}{|c|c|}
\hline C.Lalnunmawia ${ }^{1}$ & $\begin{array}{l}{ }^{1} \text { Research Scholar, Department of Economics, } \\
\text { Mizoram University, Aizawl, Mizoram, India }\end{array}$ \\
\hline Dr. Lalhriatpuii ${ }^{2}$ & $\begin{array}{c}{ }^{2} \text { Professor, Department of Economics, Mizoram } \\
\text { University, Aizawl, Mizoram, India, }\end{array}$ \\
\hline
\end{tabular}

\author{
ABSTRACT \\ Article DOI URL: https://doi.org/10.36713/epra6610
}

Purpose: The study intends to examine the incidence and intensity of multidimensional poverty and inequality in Zawlnuam RD. Block of Mizoram, India. The core objective of the study is to compute Multidimensional Poverty Index (MPI) and compare and contrast the result across the study area. We also examined the degree of inequality in deprivations among people using variance of the deprivation scores.

Methodology: This study was based on primary data which was collected through a multi-stage sampling technique. At the first stage, Zawlnuam RD. Block was selected. The second stage involved random selection of 5 villages from the RD, Block. Requisite data were then collected randomly through structured questionnaires which was designed based on the requirement for computation of Multidimensional Poverty Index. From the collected data, the incidence of poverty (headcount ratio), the intensity of poverty, and MPI were computed using Alkire-Foster Method. The study follows the 'Global MPI Brief Methodological Note, 2017 ' (Alkire \& Roble, 2017 ) in the choice of dimensions, indicators, thresholds and weights assigned to each indicator.

Results: From the result of the analysis, the multidimensional poverty in the study area is moderate. Decomposition of MPI by population sub-group reveals that poverty is most severe in Kolalian village followed by Thinghlun village, while Decomposition of MPI by component indicators show malnutrition as the most prevailing deprivation in the study area. The degree of inequality measured by variance of deprivation score ranges between 0.03 and 0.12 indicating low degree of inequality.

Applications of this study: The findings of the study can be based for formulation of government poverty reduction policies and can be used effectively in improving the existing poverty reduction strategies in the state.

KEY WORDS: Multidimensional Poverty, Inequality, Zawlnuam RD Block, Mizoram. 


\section{INTRODUCTION}

In India, poverty has been measured in single dimension from the earliest estimate of poverty by Dadabhai Naoroji to the latest estimate by Rangarajan Committee. However, no single indicator like income or expenditure can capture multiple aspects that contribute to poverty. Poor not only suffer income poverty, but several deprivations. Owing to the limitation of single dimension to capture multiple deprivations, many institution and researcher had developed a set of composite indices to measure multidimensional poverty. For example: The United Nation Development Programme's Human Development Index ((UNDP, 1998) and Amartia Sen's Capability Approach (Sen, 1999) were based on multidimensional aspect.

The emergence of Human Development Index (HDI) as a measure of overall development has shaped the perspective of the academicians, experts and scholars over the issue of development. Yet, the HDI fails to capture the level as well as intensity of poverty of a country. Sen's Capability Approach (Sen,1999) is one of the most impressive approaches to assess the well-being of individual. However, the capability approach also has its own limitations in its application to real world since the interpretation and measurement of capability is subjective. The persistent problem in measuring poverty or well-being in multidimensional aspect is not only identifying dimensions to be included, but also the issue of data availability. The remarkable milestone was seen in 2010, when Multidimensional Poverty Index (MPI) was introduced by Oxford Poverty and Human Development Initiative (OPHI) and UNDP to measure acute poverty. Since, MPI measures those experiencing multiple deprivations; arguably it is a better measure of poverty than the single dimension.

Recently, Multidimensional Poverty Index (MPI) has gained popularity owing to its comprehensive coverage of dimensions (viz, Education, Health and Standard of Living) and the decomposability of the index itself. Apart from that requisite data for the computation of MPI are not difficult to collect. In Mizoram, poverty has not been studied in terms of multidimensional aspects. It is therefore, an opportunity as well as a challenge to study incidence and intensity of multidimensional poverty in Mizoram.

\section{OBJECTIVES OF THE STUDY}

1. To examine the incidence and intensity of multidimensional poverty in the study area.

2. To compute MPI and decompose by dimensions and component indicators.

3. To compare and contrast the degree of inequality across the study area.

\section{METHODOLOGY}

\subsection{Sampling Design}

The study was mainly based on primary data. However, secondary data were also collected from various publish report like, Mizoram Below Poverty Line Survey 2016, Mizoram Economic Survey and Mizoram Statistical Handbook, etc. For the collection of primary data, a multi-stage random sampling technique was adopted. At the first stage, Zawlnuam block was selected among the three blocks in Mamit district, Mizoram. At the second stage, five villages were selected for conducting the survey. The last stage involves random selection of ten households from each village. Requisite data were then collected through structured questionnaires.

\subsection{Data Analysis}

The Alkire-Foster Method (Alkire, Foster, et.al. 2015) of measuring multidimensional poverty was employed in this study. The study followed 'Global MPI Brief Methodological Note, 2017' (Alkire \& Roble, 2017 ) in the choice of dimensions, indicators, thresholds and weights assigned to each indicator as presented in table-1 below. 
Table-1: Dimensions, Indicators, Thresholds and Weights assigned to each Indicator

\begin{tabular}{|c|c|c|c|}
\hline Dimensions & Indicators & Deprived if... & Weight \\
\hline \multirow{2}{*}{ 1. Education } & $\begin{array}{l}\text { Years of } \\
\text { Schooling }\end{array}$ & $\begin{array}{l}\text { No household member aged } 10 \text { years or older has } \\
\text { completed five years of schooling. }\end{array}$ & $1 / 6$ \\
\hline & $\begin{array}{c}\text { School } \\
\text { Attendance }\end{array}$ & $\begin{array}{l}\text { Any school-aged child is not attending school up to the } \\
\text { age at which he/she would complete class } 8\end{array}$ & $1 / 6$ \\
\hline \multirow{2}{*}{ 2. Health } & $\begin{array}{c}\text { Child } \\
\text { Mortality } \\
\end{array}$ & $\begin{array}{l}\text { Any child has died in the family in the five-year period } \\
\text { preceding the survey. }\end{array}$ & $1 / 6$ \\
\hline & Nutrition & $\begin{array}{l}\text { Any adult under } 70 \text { years of age or any child for whom } \\
\text { there is nutritional information is undernourished in } \\
\text { terms of weight for age. }\end{array}$ & $1 / 6$ \\
\hline \multirow{6}{*}{$\begin{array}{l}\text { 3. Living } \\
\text { Standard }\end{array}$} & Electricity & The household has no electricity & $1 / 18$ \\
\hline & $\begin{array}{l}\text { Improved } \\
\text { Sanitation }\end{array}$ & $\begin{array}{l}\text { The household's sanitation facility is not improved or it } \\
\text { is improved but shared with other households. }\end{array}$ & $1 / 18$ \\
\hline & $\begin{array}{c}\text { Improved } \\
\text { Drinking } \\
\text { Water }\end{array}$ & $\begin{array}{l}\text { The household does not have access to improved } \\
\text { drinking water or safe drinking water is at least a } 30 \text { - } \\
\text { minute walk from home, roundtrip. }\end{array}$ & $1 / 18$ \\
\hline & Flooring & $\begin{array}{l}\text { The household has a dirt, sand, dung, or 'other' } \\
\text { (unspecified) type of floor. }\end{array}$ & $1 / 18$ \\
\hline & Cooking Fuel & The household cooks with dung, wood or charcoal. & $1 / 18$ \\
\hline & $\begin{array}{l}\text { Assets } \\
\text { ownership }\end{array}$ & $\begin{array}{l}\text { The household does not own more than one of these } \\
\text { assets: radio, TV, telephone, bicycle, motorbike, or } \\
\text { refrigerator, and does not own a car or truck. }\end{array}$ & $1 / 18$ \\
\hline
\end{tabular}

Source: Global MPI Brief Methodological Note,2017

\subsection{Computation of MPI}

Two steps are involved in the computation of MPI:

Step 1: Individual assessment based on household achievements to determine if he/she is below the deprivation cut-off in each indicator. People below a particular deprivation cut-off are given a score of 1 and are considered deprived in that indicator whereas people above the deprivation cut-off are given a score of 0 and are considered as non-poor.

Step 2: The deprivation of each individual is weighted by the indicator's weight. If the sum of the weighted deprivations is 33 percent or more of possible deprivations, the person is considered to be multidimensionally poor or MPI poor.

MPI is a product of two parameters viz. (1) the incidence of poverty denoted as $\mathrm{H}$ and (2) the intensity of poverty denoted as A.

Formally, the first component is called the multidimensional headcount ratio $(\mathrm{H})$ and can be expressed as;

$\mathrm{H}=\frac{\mathrm{q}}{\mathrm{n}^{\prime}}$

Where, $\mathrm{H}$ is multidimensional headcount ratio, $\mathrm{q}$ is the number of people who are multidimensionally poor and $\mathrm{n}$ is the total population.

The second component measures the breadth of poverty and is calculated by following formula;
$\mathrm{A}=\frac{\sum_{\mathrm{i}=\mathrm{Ci}(\mathrm{k})}^{\mathrm{n}}}{\mathrm{q}}$,

Where, A is the intensity of poverty, $\mathrm{Ci}(\mathrm{k})$ is the censored deprivation score of individual $i$ and $q$ is the number of people who are multidimensionally poor.

The MPI is then calculated by multiplying the incidence of poverty $(\mathrm{H})$ and the intensity of poverty (A) and can be expressed as; $\mathrm{M}_{0}=\mathrm{H} \times \mathrm{A}$.

\subsection{Decomposition of MPI by Population Sub-Groups}

The study also decomposed MPI by population sub-groups. Decomposition by population sub-group simply refers to calculation of MPI for a particular group/area after which the contribution of each group/area can be calculated by the following formula;

Contribution of Sub-Group to $\mathrm{M}_{0}=\frac{\frac{\mathrm{n}_{\mathrm{i}}}{\mathrm{n}} \mathrm{MPI}_{\mathrm{i}}}{\text { Overall MPI }} \mathrm{X} 100$

Where, $M_{0}$ the overall MPI, $n_{i}$ is the population of $i^{\text {th }}$ group and $n$ is the total population. MPI is the MPI of $\mathrm{i}^{\text {th }}$ Group,

\subsection{Decomposition of MPI by Dimensions and Indicators}

The MPI can also be decomposed by computing the censored headcount ratio in each indicator multiplied by their respective weight assigned. The censored headcount ratio of an indicator or a dimension denotes the proportion of the MPI poor who 
are both multidimensionally poor and simultaneously deprived in that indicator or dimension. After decomposing by component indicators, the contribution of each indicator can be worked out by the following formula;

Contribution of indicator $\mathrm{i}$ to $\mathrm{M}_{0}=\frac{\text { Wi CHi }}{\text { Overall MPI }} \mathrm{X} 100$

Where, $\mathrm{w}_{\mathrm{i}}$ is the weight of $\mathrm{i}^{\text {th }}$ indicator and $\mathrm{CHi}$ is the censored headcount ratio of $\mathrm{i}^{\text {th }}$ indicator.

Contribution of each dimension is simply adding up the contribution of each indicator within the dimension.

\subsection{Inequality Measures}

Inequality in deprivation is also computed from deprivation score of the people by variance of deprivation score which is the third component of MPI and is denoted as $\mathrm{V}^{1}$. It is expressed as;

$\mathrm{V}^{1}=\frac{\mathrm{B}}{\mathrm{n}} \sum_{\mathrm{i}=1}^{\mathrm{q}}\left[\mathrm{C}_{\mathrm{i}}(\mathrm{k})-\mathrm{A}\right]^{2}$,

Where, $\mathrm{C}_{\mathrm{i}}(\mathrm{k})$ is deprivation score, $\mathrm{A}$ is the average deprivation score, $\mathrm{n}$ is the number of observation and $\mathrm{B}$ is the normalization parameter. The value of $\mathrm{B}$ can be chosen in such a way that the value of the inequality measure is bounded between 0 and 1 , as is true of any standard inequality measure. We set $\mathrm{B}=4$, this is the value which ensures that the inequality measure is bounded between 0 and 1 .

\section{AREA OF STUDY}

Zawlnuam block is one of the three rural development blocks in Mamit district of Mizoram. As per 2011 census, Mizoram has eight districts, out of which Mamit district is the most backward district in term of various socio-economic indicators. Being a backward region in the state, National Institute for Transforming India Aayog (NITI Aayog) also identified the district to be one of the 117 aspirational districts in India. Zawlnuam block, being a part of Mamit district was selected so as to reveal how far the block has experienced multiple deprivations and examine the incidence and intensity of multidimensional poverty.

There are 9,712 households with 47,188 population in Zawlnuam block. The block has 2 towns and 66 villages. The socio-economic profile of Zawlnuam block as per 2011 census is presented in table 2 below.

Table 2: Socio-Economic Profile of Study Area

\begin{tabular}{|c|c|c|c|}
\hline Items & Total & Urban & Rural \\
\hline Pulation & 47,188 & 35,571 & 11,617 \\
\hline Children (0-6 years) & 8,634 & 6,843 & 1,791 \\
\hline Literacy & $82.61 \%$ & $78.46 \%$ & $94.72 \%$ \\
\hline Sex Ratio & 928 & 928 & 929 \\
\hline Scheduled Caste & $0.1 \%$ & $0.1 \%$ & $0.1 \%$ \\
\hline Scheduled Tribe & $93.1 \%$ & $92.9 \%$ & $93.8 \%$ \\
\hline
\end{tabular}

Source: Census of India, Government of Mizoram

\section{RESULT AND DISCUSSION}

5.1 Overall State of Multidimensional Poverty: The overall scenario of multidimensional poverty in Zawlnuam block is shown in table 2 below.

Table 3: Measures of Multidimensional Poverty

\begin{tabular}{|c|c|}
\hline \multicolumn{2}{|c|}{ Zawlnuam Block } \\
\hline Measures & Value \\
\hline Headcount Ratio (H) & 0.38 \\
\hline Intensity of Poverty (A) & 0.41 \\
\hline $\begin{array}{c}\text { MPI also known as Adjusted Headcount } \\
\text { Ratio }\end{array}$ & 0.16 \\
\hline
\end{tabular}

As is evidenced from table 3, Zawlnuam block has a headcount ratio of 0.38 , which means that 38 percent of the people in the study area are multidimensionally poor (i.e MPI Poor). As regard to intensity of poverty, the block recorded 0.41 indicating that the MPI poor are deprived in 41 percent of ten set of indicators. The MPI (also known as adjusted headcount ratio) in Zawlnuam block is 0.16 . This means that the proportion of weighted deprivations that the poor experienced in society is 16 percent out of the 
total potential deprivations that the society could experience.

\subsection{Decomposition of MPI by Population Sub-Groups}

Decomposing of MPI by population sub-groups (i.e block-wise) helps us to show the prevalence of poverty within and between the blocks. Table 4 below shows decomposition of MPI by population sub-group in the study area.

Table 4: Decomposition of MPI by Population Sub-group

\begin{tabular}{|c|c|c|c|c|}
\hline Villages & H & A & MPI & $\begin{array}{c}\text { Contribution to overall } \\
\text { MPI }\end{array}$ \\
\hline Thinghlun & 0.53 & 0.38 & 0.20 & 24.5 \\
\hline Hriphaw & 0.27 & 0.39 & 0.10 & 11 \\
\hline Kolalian & 0.45 & 0.65 & 0.23 & 25 \\
\hline Bungthuam & 0.37 & 0.43 & 0.16 & 13.5 \\
\hline Zamuang & 0.31 & 0.39 & 0.12 & 26 \\
\hline
\end{tabular}

Looking at the incidence of poverty in column-2 of Table 4, Thinghlun village has the highest incidence of poverty followed by Kolalian with headcount ratio of 0.53 and 0.45 respectively. The village of Hriphaw has the lowest incidence of poverty in Zawlnuam block. From the result of the analysis, Zawlnuam has high incidence of poverty ranging between $0.27-0.53$.

As demonstrated in column-3 of table 4 , the intensity of poverty ranges between $0.38-0.65$. The highest intensity of poverty is seen in Kolalian village followed by Bungthuam block with 0.65 and 0.43 respectively indicating that multidimensional poverty is more severe in these two villages. The intensity of poverty in the rest of the villages does not show any significant variation.

The analysis of incidence and intensity of poverty may look confusing and ambiguous since block with low incidence of poverty can have high intensity of poverty. In order to have a better understanding, these two pieces of information are bridged into a single number. This combined information on incidence and intensity of poverty is called MPI. If all households are multidimensionally poor (i.e. deprivation score $\geq 1 / 3$ of the indicators) then percentage of MPI poor will be 100 percent and 'headcount ratio $(\mathrm{H})$ in this case will be 1 and hence MPI will be equal to the value of intensity of poverty (A). If MPI poor, on the other hand, are deprived in all the indicators then intensity of poverty (A) in this case will be 1 and the value of MPI will be equal to headcount ratio $(\mathrm{H})$. Thus MPI reflects the proportion of weighted deprivations that the poor experience in a society out of the total potential deprivations that the society could experience.

There are certain variations in the value of MPI in the study area ranging between $0.10-0.23$. The most deprived block identified on the basis of ten set of indicators was Kolalian village with 0.23 MPI followed by Thinghlun villlage with MPI value of 0.20 . The higher value of MPI in these two villages may be attributed to the fact that these two villages are at the boundary area of Mizoram and have been mixed up by some illegal immigrants, other social categories and minorities like Bru and Chakma, which downgrades the two blocks in various aspects development. Among the five villages in the study area, Hriphaw and Zamuang outperformed other village and have relatively lower value of MPI as depicted in table 3 above.

\subsection{Decomposition of MIP by Dimension and Indicators}

While decompositions by population sub-groups show the geographical distribution of multidimensional poverty, decomposition by dimensions and indicators tell the contribution of each dimension and indicator and is helpful to identify the degree of deprivation of various dimension and indicators. Table 4 shows decomposition by dimensions and component indicators in Zawlnuam blocks. 
Table 5: Decomposition of MPI by Dimension and Component Indicators

\begin{tabular}{|c|c|c|c|c|c|}
\hline Dimensions & Indicators & $\begin{array}{c}\text { Censored } \\
\text { Headcount } \\
\text { Ratio }\end{array}$ & Weight & $\begin{array}{c}\% \\
\text { Contribution } \\
\text { of Each } \\
\text { Indicator }\end{array}$ & $\begin{array}{l}\text { \% Contribution of } \\
\text { Each Dimension }\end{array}$ \\
\hline \multirow[b]{2}{*}{ Education } & Year of Schooling & 0.11 & $1 / 6$ & 12 & \multirow[b]{2}{*}{23} \\
\hline & $\begin{array}{c}\text { School } \\
\text { Attendance }\end{array}$ & 0.11 & $1 / 6$ & 11 & \\
\hline \multirow{2}{*}{ Health } & Child Mortality & 0.05 & $1 / 6$ & 6 & \multirow{2}{*}{30} \\
\hline & Nutrition & 0.19 & $1 / 6$ & 24 & \\
\hline \multirow{6}{*}{$\begin{array}{l}\text { Living } \\
\text { Standard }\end{array}$} & Electricity & 0.04 & $1 / 18$ & 1 & \multirow{6}{*}{47} \\
\hline & Water & 0.28 & $1 / 18$ & 10 & \\
\hline & Sanitation & 0.13 & $1 / 18$ & 5 & \\
\hline & Cooking Fuel & 0.27 & $1 / 18$ & 10 & \\
\hline & Flooring & 0.35 & $1 / 18$ & 13 & \\
\hline & Assets & 0.21 & $1 / 18$ & 8 & \\
\hline
\end{tabular}

Source: Computed from Field Survey Data, 2019.

Table 5 shows censored headcount ratio, percentage contribution of dimensions and indicators. Important point to be noted is that indicator having larger value of censored headcount ratio can have smaller contribution to MPI because of different weights assigned to indicators.

As shown in table 5, the dimension of standard of living is the largest contributor to overall MPI of the study area with 47 percent. This signifies the overall low standard of living in the study area. The second largest contributor to overall MPI of the block is the dimension of health with 30 percent. The least contributor is education dimension having a contribution of 21 percent. The contribution of education dimension, being the least, finely suits the existing record of Mizoram literacy rate. Mizoram has been known for its notable performance in literacy rate even at national level. However, this does not mean that the two indicator of education dimension (i.e. year of schooling and school attendance) are excellent in Mizoram. It means the summing up of censored headcount ratio of the two indicators adjusted by the weight of the indicator is relatively less than other indicators.

Decompositions by indicators show the degree of specific deprivations that people experienced. Nutrition has surpassed all other indicators with 24 percent contribution to overall MPI of the block followed by the indicator of flooring with 13 percent. Years of schooling unexpectedly become the third largest contributor with 12 percent followed by school attendance with 11 percent. One should not confuse the results of decomposition by dimensions with that of the results given by indicators. The contribution of each dimension to overall MPI is simply adding up the contribution of each indicator within the dimension, so that the dimension which contributes least to overall MPI can have indicator which make largest contribution to overall MPI. In the previous analysis, it was found that educational dimension is the least contributor to overall MPI. However, if MPI is further decomposed beyond dimensions into indicators, years of schooling, which is part of educational dimension, occupies the third most deprivation in the study area. The analysis reveals that the deeper the decomposition is carried out, the clearer is the means of deprivation that people suffered most. From the result of the analysis, the indicator of year of schooling is still a big concern in the study area for the Government.

Considering the weight assigned to the indicators (i.e 0.165), the contribution of water and cooking fuel with 10 percent each is an alarming result and need more attention. This is because of the fact that the censored headcount ratio of each indicator is adjusted by their respective weight assigned. The smaller the weight assigned, the greater is the degree of reducing the censored headcount ratio of the indicator. Thus, indicators where most people deprived still can contribute only small percentage to overall MPI due to small weight assigned. This is the case of cooking fuel and water where most people in the study area are deprived of clean cooking fuel and water, yet the contribution made by these indicators cannot make a sharp rise. The contributions of the rest of the indicators show slight differences ranging between 5-8 percent except the indicator of electricity.

The contribution of electricity to overall MPI is 0.25 which is very close to zero. This record depicts the fact that electricity has reached out the last mile in the study area. The result is also in line with the record of the Power and Electricity Department, Government of Mizoram, which recorded that hundred percent 
electricity connections has been completed under Deen Dayal Upadhyaya Yojana (DDUGKY) and Saubhayga

\section{INEQUALITY IN DEPRIVATION}

The third important component of MPI is a measure of Inequality in deprivation denoted as $\mathrm{V}^{1}$. It is the variance of the deprivation score which is normalised between 0 and 1 . When all the poor people have the same level of deprivation scores, there is no scheme.

inequality, and the value of $\mathrm{V}^{1}$ is equal to 0 . The measure of $\mathrm{V}^{1}$ takes the value of 1 when half of the poor people have the maximum possible deprivation score of 1 and the rest have the minimum possible deprivation score of 0 .

Table 6: Inequality in Deprivation Score

\begin{tabular}{|c|c|c|c|}
\hline & A & MPI & $\mathbf{V}^{\mathbf{1}}$ \\
\hline Villages & & & \\
\hline Thinghlun & 0.38 & 0.20 & 0.03 \\
\hline Hriphaw & 0.38 & 0.10 & 0.06 \\
\hline Kolalian & 0.65 & 0.23 & 0.12 \\
\hline Bungthuam & 0.43 & 0.16 & 0.08 \\
\hline Zamuang & 0.39 & 0.12 & 0.07 \\
\hline
\end{tabular}

Since, the variance measure, $\mathrm{V}^{1}$ is sensitive to high deprivation score; village with higher value of intensity of poverty (A) has larger value of $\mathrm{V}^{1}$ as is evidence from table 6 . The village of Kolalian has highest value of $\mathrm{V}^{1}$ followed by Bungthuam. These two villages also have the two highest intensity of poverty.

Village having higher value of intensity of poverty signifies that the proportion of deprivation experienced in ten set of indicators are relatively more than other villages. Thus, villages with high intensity of poverty are more likely to have higher value of $\mathrm{V}^{1}$. Likewise, the MPI and $\mathrm{V}^{1}$ also demonstrate certain pattern of relationship. Generally, the higher the value of the MPI, the higher is the value of $\mathrm{V}^{1}$, but this does not mean that, village with higher value of MPI should have higher value of $\mathrm{V}^{1}$. It is possible to have same value of MPI but different value of $\mathrm{V}^{1}$.

The lowest value of $\mathrm{V}^{1}$ is seen in Thinghlun village with 0.03 , followed by Hriphaw with 0.06 . These two villages have same value of intensity of poverty but significantly different value of MPI. Surprisingly, Thinghlun village with lower MPI value has higher value of $\mathrm{V}^{1}$ signifying that there can be high degree of inequality even when the village enjoyed low value of MPI.

\section{SUGGESTION}

The most important recommendation that can be made from the empirical analysis is developing poverty measure that would capture the spread and intensity of poverty in Mizoram. In this study, we employed the method of Global MPI for calculating the level of multidimensional poverty in Zawlnuam block. The study found 38 percent of people who are multidimensionally poor. This figure is far behind the poverty data of Mizoram released by Planning Commission in 2004-05 and 2011-12. According to Planning Commission, Mizoram has 15.3 percent of BPL in 2004-05 based on Tendulkar methodology which jumped up to 20.4 percetn in 2011-12. In 2016, Directorate of Economics \& Statistics, Government of Mizoram, has conducted BPL baseline survey in the State with new methodology. The report was released in June 2018 in which 19.64 percent families are living Below Poverty Line which falls behind the finding of the study. It is thus clear that number of BPL families depend upon the methodology adopted to determine whether a family is below the estimated poverty line. In order to acquire the solid and reliable information on poverty, it is the need of the hour to developed poverty measure that would capture the ground reality.

\section{CONCLUSION}

In this study, we measured the level of multidimensional poverty and inequality in Zawlnuam block using Global Multidimensional Poverty Index Methodological Note, 2017, developed by Oxford Poverty and Human Development Initiative, University of Oxford. We also decomposed MPI by dimensions, indicators and population sub-groups. From result of the analysis, it was found that people are suffering multiple deprivations in varying degrees. The level of inequality in deprivation is fortunately lower than expected indicating that the level of poverty or wellbeing is horizontally equal to some extent. The findings are expected to have empirical insights for effective policy formulation, which, in turn, will contribute to the improvement for the welfare of the people in Mizoram. 


\section{REFERENCES}

1. Alikire S., (2010), 'Multidimensional Poverty and its Discontents', OPHI Working Pape,r No. 46, Oxford Poverty and Human Development Initiative, University of Oxford.

2. Alkire, $S \&$ Roble, G. (2017), 'Multidimensional Poverty Index: Brief Methodological Note and Results', Oxford Poverty and Human Development Initiative, University of Oxford. .

3. Dehury, et.al (2015), 'Regional Estimates of Multidimensional Poverty in India', Economics Discussion, Paper No. 2015-34, pp.1-23, May

4. Directorate of Economics \& Statistics, Government of Mizoram.

5. Dotter C., et.al (2014), 'The Concept of Relative Multidimensional Poverty: An Illustration Using Indian DHS Data', IARIW, Netherlands.

6. Economics Survey, Planning \& Programme Implementation Department, Government of Mizoram, 2018-19.

7. Mizoram Below Poverty Line Surve), Directorate of Economics \& Statistics, Government of Mizoram, 2016.

8. Mohanty (2011), 'Multidimensional Poverty and Child Survival in India', Public Library of Science, Vol.6, No. 10, , pp.1-14, October.

9. Population Census (2011), Registra General of India, Government of India, .

10. Preeti (2015), 'Interstate Comparison of Poverty Status in India' International Journal of Management and Social Sciences Research, Vol. 4, No. 5, pp.39-43, May.

11. Rao Jasmine (2010), 'The Caste System: Effects on Poverty in India, Nepal and Sri Lanka', Global Majority E-Journal, Vol. 1, No. 2, pp. 97-106, December.

12. Rouf Kazi Abdur (2015), 'While Poverty is a Global Problem Resulting from Global Issues, its Definition and Solution can only be Found Locally', Global Journal of Management and Business Research: B Economics and Commerce, Vol. 15, No.7.

13. Sarania Rahul (2015), 'Analysis of Poverty Profile and Determinants of Welfare among Rural Households: A Case Study of Udalguri District, Assam', International Journal of Humanities \& Social Science Studies, Vol.-I, No.-IV, pp. 138-144, January.

14. Sen Amartya (1999), Development as Freedom, Alfred A.Knopf, Inc. New York.

15. Seth S. \& Alkire S. (2014), 'Measuring and Decomposing Inequality among the Multidimensionally Poor Using Ordinal Data: A Counting Approach', OPHI Working Paper, No. 68, Oxford Poverty \& Human Development Initiative, University of Oxford.

16. Seth $S \&$ Alkire S. (2014), 'Inequality Among the MPI Poor, and Regional Disparity in Multidimensional Poverty: Levels and Trends', Oxford Poverty \& Human Development Initiative, University of Oxford
17. United Nation Human Development Report (1998), United Nation Development Programme, New York, United States.

18. UN official Website: (https://www.un.org/esa/socdev/wssd/textversion/agreements/poach2.htm)

19. Village Profile and Developments Indicators (2017-18).

20. Vijay et.al (2014), 'Moving from the Household to the Individual: Multidimensional Poverty Analysis', World Development, Vol.59, Issue C, , pp.70-81, February.

21. Yusuf Nadia (2014), 'Role of Rural Finance in Reduction of Poverty in the Agriculture Sector: Northern India', International Journal of Business and Economic Development, Vol. 2, No. 2, pp.97105, July.

22. Seth $S$ \& Alkire S. (2014), 'Inequality Among the MPI Poor, and Regional Disparity in Multidimensional Poverty: Levels and Trends', Oxford Poverty \& Human Development Initiative, University of Oxford 